\title{
EFFECTS OF LIQUID AND LOW ANALYSIS FERTILISERS ON PASTURE AND ANIMAL PRODUCTION
}

C. Feyter ${ }^{1}$, D.C. Edmeades ${ }^{1}$,M.B. O'Connor' and C. E. Smart ${ }^{2}$

${ }^{1}$ Ruakura Agriculture Centre, MAF, Hamilton

${ }^{2} \mathrm{c} / \mathrm{O}$ MAF, Te Kuiti

Abstract

The effects on pasture production of 4 liquid fertilisers, Maxicrop ${ }^{\star}, \mathrm{N}-\mathrm{Fix}^{\bullet}$, Response $^{\oplus}$, and Plant Plasma and two proprietary solid fertilisers Natumix and Wright's Mix were examined in a series of 3 trials over a 2-year period near the Ruakura Agriculture Centre. None of the liquid materials significantly affected total pasture production over the trial periods This is consistent with international summaries of trials with seaweed and fish extracts which concluded that such materials have no consistent effect of practical benefit on pasture and crop production. Plant Plasma applied at 10 times the recommended rate, boosted pasture production in the first harvest after each application, as did Plant Plasma at the normal rate after one of the applications. The proprietary fertilisers performed as could be predicted from their nutrient contents. In a grazing trial near Te Kuiti. Response Extra* had no significant effects on any of 8 measures of animal performance, or on pasture production in that trial or in an associated small-plot trial. None of the liquid or proprietary solid fertilisers, applied at recommended rates, had consistent effects on pasture botanical and chemical composition or soil test levels.

Keywords: seaweed extracts fish extracts, low analysis fertilisers, pasture production, animal production

\section{INTRODUCTION}

Reduced farm incomes, coupled with escalating fertiliser prices, have prompted many farmers to reduce fertiliser costs by reducing rates or frequency of application or by changing to lower cost materials. Some farmers have switched to low analysis proprietary fertilisers. Others have been attracted to liquid seaweed or fish-based materials by vigorous promotion and because of their apparent low costs. Some users of liquid fertilisers are convinced of their benefits.

Seaweed extracts have been marketed in New Zealand for more than 25 years and fish extracts have been available from about 1980. Claims made for these materials range from 'complete fertiliser and 'source of trace elements' to 'soil modifier' and 'growth promoter.

Effects of 12 liquid fertilisers on growth and nutrient uptake of ryegrass grown in washed sand were examined in pot trials at the Ruakura Agriculture Centre in 1984. The liquids were applied at 2 concentrations and with either a high or a low basal nutrient supply. Two of the 12 ( $\mathrm{N}$-Fix and Plant Plasma) consistently increased ryegrass growth when they were applied at the higher concentration and in the presence of a high basal nutrient supply. Plant Plasma also increased uptake of phosphorus (P) and sulphur (S) with the low nutrient supply (I.S. Cornforth, pers. comm.).

After these pot trials, it was decided to test some of the liquid fertilisers in a series of 3 field trials near the Ruakura Agriculture Centre. Two proprietary solid fertilisers were included in one of the trials. One of the liquid fertilisers was also examined in a hill country grazing trial, and an associated small plot trial. Animal performance as well as pasture production was measured in the grazing trial. Results from this work and their practical implications are reported in this paper and discussed in relation to existing knowledge about liquid and low analysis fertilisers. 


\section{METHODS}

The Ruakura trials were conducted on a Bruntwood silt loam (Aquic Dystrandept). The site was in permanent grass-clover pasture, which had received at least 4 applications of $375 \mathrm{~kg} 30 \%$ potassic superphosphate $(26 \mathrm{~kg} \mathrm{P}, 56 \mathrm{~kg} \mathrm{~K}$ ) per ha at yearly intervals. Pasture production averaged $8.7 \mathrm{t} \mathrm{DM} / \mathrm{ha} /$ year and the soil had a pH of 5.6, Olsen $P$ test of 12 and potassium $(K)$ test of 6 . In trial 1 the seaweed extracts Maxicrop $(M)$ and Response@(R), the fish extract Plant Plasma ${ }^{\oplus}$ (PP) and the biological supplement N-Fix@ (NF) were applied at recommended rates both in the absence and presence of traditional fertilisers at rates recommended for the nutrient status of the site $(50 \mathrm{~kg} \mathrm{P}$ and $46 \mathrm{~kg} \mathrm{~K}$ per ha) (PKS) (Table 1).

Table 1: Trial treatments and macro-element application rates

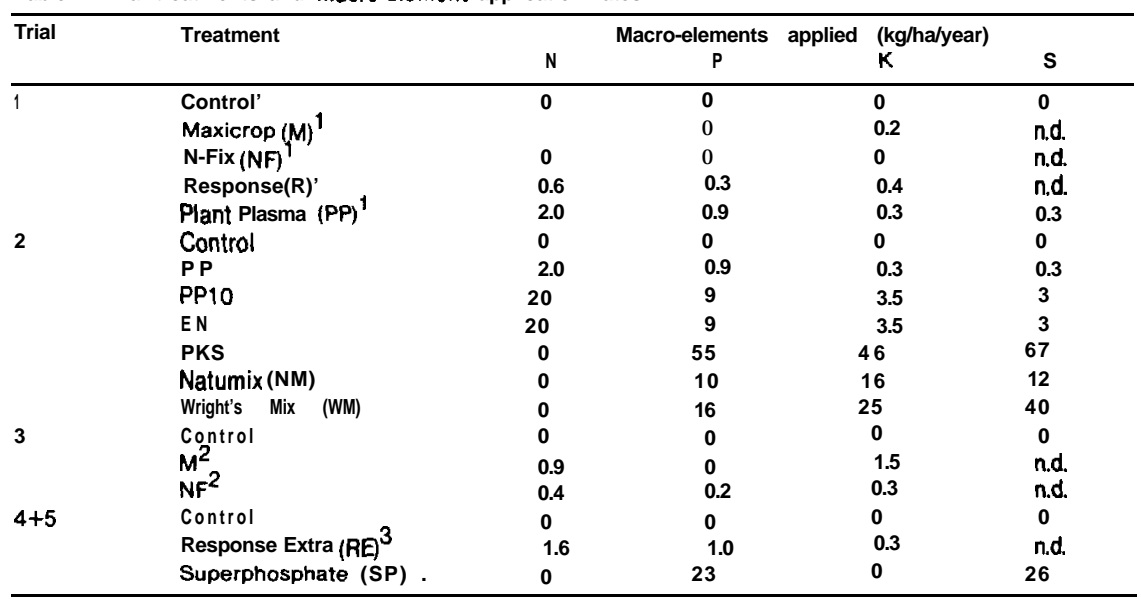

PP10 $=$ PP at 10 times the recommended rate of application.

$\mathrm{EN}=$ Nutrients equivalent to PP1O as inorganic solid fertilisers.

PKS = Traditional fertilisers at rates recommended for the nutrient status of the site (50 kg P and $46 \mathrm{~kg} \mathrm{K/ha)}$.

1 Applied in the absence and presence of PKS.

Re-applied after each harvest

3 Applied twice yearly.

n.d not determined.

Trial 2 included PP at recommended and 10 times the recommended rate (PP1 0) and the equivalent of PP10 as inorganic solid fertilisers (EN), also PKS and the proprietary fertilisers Natumix $(N M)$ and Wright's Mix ${ }^{\circ}(W M)$ at $500 \mathrm{~kg} / \mathrm{ha}$ (Table 1). NM and WM were mixtures of organic or inorganic waste materials and traditional fertilisers. Neither are now marketed in the same form.

In trial 3, M and NF were re-applied after each harvest (8-10 times/year) (Table 1). There were 5 replicates in trial 1 and 4 in trials 2 and 3; plot size was $5 \mathrm{~m} \times 2 \mathrm{~m}$. Treatments in all 3 trials were applied by hand, using a hand sprayer for the liquids, in November 1985 and again in September 1986. All 3 trials were harvested 18 times from December 1985 to November 1987 at intervals of at least 21 days Forty percent of clippings from each harvest were returned to the plots to simulate recycling of nutrients in a grazed sward. Botanical compositions were determined 4 times, chemical compositions 3 times and soil samples $(0-80 \mathrm{~mm})$ were collected and analysed twice.

Trials 4 and 5 were conducted from March 1986 till December 1987 on a Te 
Kuiti silt loam (Typic Vitrandept) at the Te Kuiti Research Area Trial 4 included 3 equal sized farmlets of 6 paddocks (average size 0.493 ha) each. One farmlet received no fertiliser (Control), one received 2 applications of Response Extra@ (RE) per year sprayed on to the pasture at $5 \mathrm{l} / \mathrm{ha}$ and the third was topdressed annually with $250 \mathrm{~kg}$ of superphosphate (SP) per ha (Table 1). The farmlets were stocked with matched groups of ewes at 18 per ha. Paddocks were set stocked from before lambing (August) to weaning (November) and rotationally grazed at other times. Pasture production was assessed through calibrated visual assessments and animal performance by measuring ewe and lamb liveweights and wool production over two seasons.

Trial 5 consisted of 4 replicates of $5 \mathrm{~m} \times 1.5 \mathrm{~m}$ plots with the same treatments as in trial 4, laid down in each of 2 paddocks of the Control farmlet. Pasture production was measured with small cages. Herbage chemical compositions were determined once for trial 4 and 4 times for trial 5 . Soil tests were taken twice from the topsoil 10 $80 \mathrm{~mm})$ and the subsoil $(80-150 \mathrm{~mm})$ of trial 4 and from the topsoil of trial 5 .

\section{RESULTS AND DISCUSSION}

None of the liquid fertilisers investigated had a statistically significant effect on total pasture production (Fig. 1), irrespective of whether applied in the absence or presence of traditional fertiliser (trial 1), applied once only or repeatedly (trials 3, 5 and 5) or at a higher than recommended rate (PPy 0, trial 2). RE had no significant effect on animal performance in the grazing trial (Table 2). In contrast, SP increased 6 of the 8 animal performance parameters and also increased pasture production in the associated small-plot trial by $11 \%$ (Fig. 1). The $6 \%$ increase in pasture production in the grazing trial with $\mathrm{SP}$ failed to reach significance.

Table 2: Ewe and lamb liveweight and wool production measurements, trial $4 \mathbf{~ ( k g ) . ~}$

\begin{tabular}{llcccc}
\hline \multicolumn{1}{r}{ Variable } & Year & Control & RE & SP & Lsd (5\%) \\
\hline $\begin{array}{l}\text { Ewe liveweights } \\
\text { (weaning) }\end{array}$ & 1966 & 50.2 & 51.9 & $56.5^{*}$ & 4.6 \\
& 1967 & 47.4 & 47.4 & $56.3^{\prime}$ & 4.5 \\
Ewe wool yield & 1966 & 4.07 & 3.91 & $4.71^{\star}$ & 0.26 \\
& 1967 & 4.09 & 3.93 & $4.66^{\prime}$ & 0.26 \\
Lamb liveweights & 1966 & 19.14 & 19.90 & $21.20^{\prime}$ & 1.61 \\
(weaning) & 1987 & 19.45 & 17.71 & 19.75 & 2.93 \\
Lamb wool yield & 1966 & 0.70 & 0.71 & $0.61^{\prime}$ & 0.06 \\
& 1967 & 0.73 & 0.62 & 0.72 & 0.13 \\
\hline
\end{tabular}

\section{$. P<0.05$}

The performance of the liquid fertilisers in these trials is consistent with the summary of 142 world-wide trials (21 on pasture) with $\mathbf{M}$ by Edmeades (1987). He found that apparent effects of $M$ were as often negative as they were positive. Crop (including pasture) production was significantly $(5 \%)$ increased in 8 and reduced in 5 out of 290 measurements. This, and similar results from 218 trials with other seaweed extracts (11 on pasture), led to the conclusion that such materials have no consistent effect of practical value on pasture and crop production (Edmeades 1987). A summary of results from 63 trials with fish-based foliar fertilisers showed that they also had no significant effects of practical value on the production of a range of crops (DC. Edmeades unpublished data).

The lack of positive effects of the liquid fertilisers in these trials is consistent 


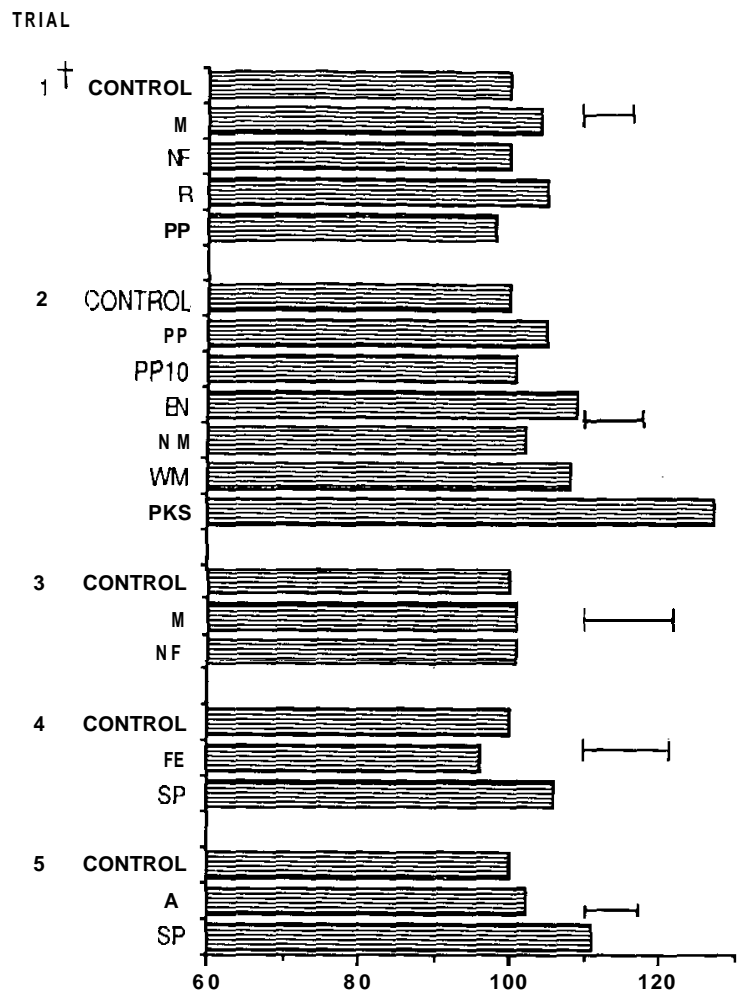

RELATIVE (CONTROL $=100$ ) PASTURE PRODUCTION OVER TOTAL TRIAL PERIODS

$t$ Means of effects in the

absence and presence of

PKS

Figure 1: Relative (Control $=100$ ) total pasture production in all trials. $M=$ Maxicrop, NF=N-Fix. $R=R e s p o n s e$ $\mathrm{PP}=$ Plant Plasma, PP10=Plant Plasma at 10 times the recommended rate, EN=Equivalent nutrients to PP10 $\mathrm{NM}=$ Natumix, $W M=$ Wright's $M \mathrm{ix}, \mathrm{RE}=$ Response Extra, $\mathrm{SP}=$ Superphosphate, $\mathrm{PKS}=$ traditional fertilisers at recommended rates

Table 3: Rates of trace elements ( $\mathrm{g} / \mathrm{ha}$ ) applied in standard applications of liquid fertilisers, as impurities in $\mathbf{5 0 0}$ $\mathrm{kg} / \mathrm{ha}$ superphosphate (Super) and in standard applications lo rectify or prevent trace element deficiencies (Standard).

\begin{tabular}{lcccr}
\hline Fertiliser & Zinc & Copper & Molybdenum & Cobalt \\
\hline Maxicrop & 0.02 & 0.01 & $<0.01$ & co.01 \\
N-Fix & 0.03 & 0.05 & 0.02 & 0.02 \\
Response & 0.37 & 0.44 & 0.04 & 0.03 \\
Plant Plasma & 99.20 & 1.56 & 2.48 & 0.79 \\
SuDer & $100-250$ & $2.5-25$ & $0.25-1$ & $0.5-1$ \\
Standard & 2300 & 2500 & 40 & 70 \\
\hline
\end{tabular}

with the negligible quantities of macro-elements applied in the liquids (Table 1). Although some (particularly PP) have significant concentrations of trace elements, the actual quantities applied at common application rates seldom exceed amounts of trace elements applied as impurities in SP and are negligible in comparison with 


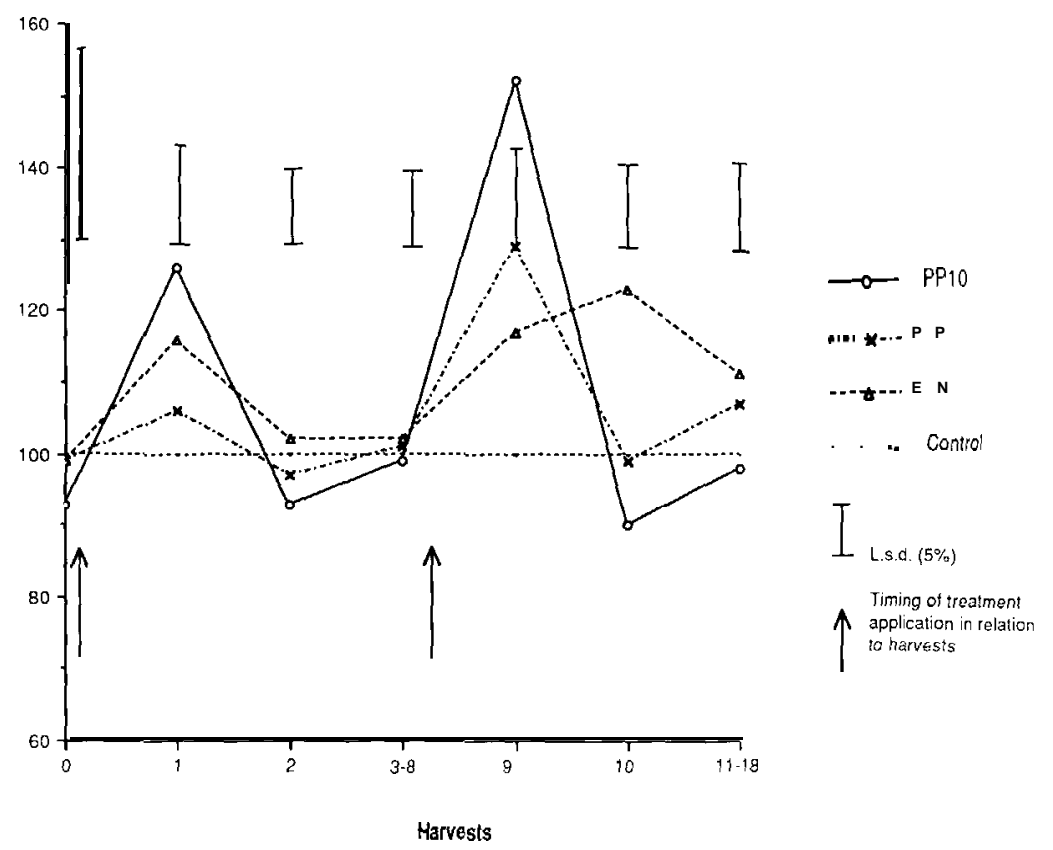

Figure 2: Relative $($ Contro $=100)$ pasture production of PP. PP10 and EN in trial 2 for some individual and some combined harvests.

Table 4: Frequency of significant $(<5 \%)$ beneficial and detrimental effects on pasture botanical and chemical composition and soil test parameters (All trials)

\begin{tabular}{lccc}
\hline Treatment & $\begin{array}{c}\text { Parameters } \\
\text { measured }\end{array}$ & $\begin{array}{c}\text { Sign. beneficial } \\
\text { effects }\end{array}$ & $\begin{array}{c}\text { Sign. detrimental } \\
\text { effects }\end{array}$ \\
\hline M & 135 & 3 & 3 \\
N F & 135 & 3 & 2 \\
R & 69 & 1 & 4 \\
PP & 138 & 4 & 4 \\
PP10 & 69 & 12 & 1 \\
E N & 69 & 4 & 0 \\
N M & 69 & 2 & 0 \\
W M & 89 & 2 & 0 \\
RE & 100 & 1 & 3 \\
SP & 100 & 11 & 3 \\
PKS & 138 & 37 & 15 \\
\hline
\end{tabular}

amounts commonly applied to rectify or prevent trace element deficiencies (Table 3).

Although the liquids may contain some plant growth substances or regulators (phytohormones), these would need to be applied at much greater concentrations (e.g. 98,000 I M/ha) to be effective in the field (Witham 1987). However, some evidence of an effect on pasture growth other than a plant nutrient effect was detected in the performance of PP10. Although this treatment produced no more than control over the total trial period and significantly less than its equivalent nutrient content in mineral form (EN, Fig. 1) it significantly boosted pasture production in the first harvest after each treatment application (Fig. 2). This effect could not always be explained in terms of amount of nutrients applied and was also 
noticeable in the PP treatment of both trials 1 and 2 after the second application.

Results from a subsidiary trial showed that the site for trials 1, 2 and 3 was mainly $\mathbf{P}$ responsive. Thus, NM and WM could be expected on the basis of their $\mathbf{P}$ contents, to increase production by 5 and $8 \%$ respectively in relation to PKS, which increased it by $27 \%$ (Fig. 1). The actual increases from NM and WM were 2 and $8 \%$, not significantly different from expectations. The results from these trials therefore support the hypothesis that the performance of fertilisers can be predicted solely from their nutrient contents.

None of the liquid and proprietary solid fertilisers applied at recommended rates had consistent effects on botanical and chemical composition of pasture or soil test levels. In contrast, PKS had beneficial effects in $27 \%$ and SP in $11 \%$ of the cases (Table 4). Detrimental effects were mainly lowered concentrations of magnesium, sodium and some trace elements, probably owing to dilution through increased pasture production or to competitive ion effects PP10 had beneficial effects on pasture composition and soil tests in $17 \%$ of the cases (Table 4). These were mainly increases in concentrations of zinc, copper and molybdenum in the herbage, but these increases had little practical value because those trace element concentrations were already adequate.

Response Extra had no positive effect on animal performance. This is consistent with the lack of any positive effect of this product on pasture production. A similar conclusion was drawn from the results of 3 grazing trials with $M$ in Otago (Metherell 1987). Given that the liquid products examined in these trials had no consistent effects on pasture production and composition or on soil nutrient levels, it is reasonable to conclude that they would also have no effect on animal health and production, despite claims to the contrary.

\section{CONCLUSIONS}

1. Results from this series of trials have confirmed that liquid seaweed or fishbased foliar fertilisers have no consistent effects on pasture production, pasture composition, soil test levels and animal production.

2. Performance of both the liquid and the proprietary solid fertilisers at recommended rates supports the hypothesis that the effectiveness of fertilisers can be predicted from their nutrient contents.

3. Plant Plasma applied at 10 times the recommended rate significantly boosted pasture production in the first harvest after each treatment application. At the recommended rate the product had a similar effect after one of the applications.

Acknowledgements

We are indebted to Martin Upsdell for statisitical analyses and to Craig Lovell, Brett Addison and Kevin Jones for field work

\section{References}

Edmeades, D.E 1987. Submiss/ on lo: Bell-Booth Group Ltd. v. Her Majesty's Attorney-General (in respect of the Ministry Of Agriculture and Fisheries) and Broadcasting Corporation of New Zealand. High Court of New Zealand, Wellington, 24 November 1987. (A333/85).

Metherell, AK 1987: Ibid.

Witham, F.H. 1987: Ibid. 